\title{
Low Dose Bupivacaine plus Fentanyl in Subarachnoid Block for Caesarean Section
}

\author{
Nasir Uddin Ahmed ${ }^{1}$, Masuda Islam Khan ${ }^{2}$, Aynul Islam Khan ${ }^{3}$, AKM Akhtaruzzaman ${ }^{4}$
}

\begin{abstract}
Background: Spinal anaesthesia induced hypotension, a common problem during caesarean section, is associated with maternal nausea and vomiting and the risk of neonatal acidosis. Low dose local anaesthetic combined with opioids spinal anaesthesia better preserves maternal haemodynamic stability, resulting in equally efficacious anaesthesia. Objectives: To investigate whether this synergistic action could be used to provide effective anaesthesia while preventing hypotension during caesarean operation. Materials and method: This prospective study included 60 pregnant mothers scheduled for caesarean operation who were then divided into two groups (thirty in each). Group-A received a spinal injection of $12.5 \mathrm{mg}$ of standardized $0.5 \%$ hyperbaric bupivacaine and group-B received $8 \mathrm{mg}$ of $0.5 \%$ hyperbaric bupivacaine with $20 \mu \mathrm{gm}$ fentanyl. Hypotension was defined as the systolic blood pressure drops below $90 \mathrm{~mm}$ of $\mathrm{Hg}$ or a decrease of systolic blood pressure $25 \%$ from pre anaesthesia level and hypotension was treated with a bolus of 5 to $10 \mathrm{mg}$ of intravenous ephedrine. The quality of anaesthesia and postoperative analgesia were evaluated. Results: The mean time required to reach peak sensory level was earlier in group- $B$ than group- $A$ and was statistically significant $(p<0.05)$. The decrease in systolic blood pressure in group- $A$ was significantly more than group $-B(p<0.05)$ and vasopressor requirement was also significantly more in group-A compared to group- $B(p<0.05)$. Mean time of two segment regression of sensory analgesia and complete sensory recovery was significantly early in group $-B(p<0.05)$. Duration of motor recovery in group- $B$ was significantly earlier $(p<0.05)$. The duration of effective analgesia was significantly more in group- $B$ $(p<0.05)$. Conclusion: Low dose Bupivacaine with fentanyl provided excellent intraoperative sensory and motor blockade, haemodynamic stability, and effective postoperative analgesia for caesarean delivery.
\end{abstract}

Keywords: Bupivacaine; caesarean delivery; fentanyl; spinal anaesthesia.

Delta Med Col J. Jan 2016;4(1):24-30

\section{Introduction}

Regional anaesthesia has become the preferred technique in caesarean section because general anaesthesia has been associated with higher maternal mortality. Deaths associated with general anaesthesia are mostly related to airway problems, such as inability to intubate or ventilate or

1. Assistant Professor, Dept. of Anaesthesia and Intensive Care Unit, National Institute of Traumatology \& Orthopedic Rehabilitation, Dhaka, Bangladesh.

2. Assistant Professor, Dept. of Obs \& Gynae, BIRDEM Hospital, Dhaka, Bangladesh.

3. Child Specialist, National Institute of Kidney Diseases \& Urology, Dhaka, Bangladesh.

4. Professor, Dept. of Anaesthesia, Analgesia \& Intensive Care Medicine, Bangabandhu Sheikh Mujib Medical University, Shahbagh, Dhaka, Bangladesh.

Correspondence: Nasir Uddin Ahmed. e-mail: masudaislamkhan@yahoo.com 
aspiration pneumonitis, whereas death associated with regional anaesthesia are generally related to extremely high neural blockade or local anaesthetic toxicity. Advantages include less neonatal exposure to potentially depressant drugs, a decreased risk of maternal pulmonary aspiration, an awake mother at the birth of her baby and with father also present if desired. ${ }^{1}$ Successful spinal anaesthesia for caesarean section requires up to $\mathrm{T} 4$ sensory block which can be achieved with 10-15 $\mathrm{mg}$ intrathecal dose of $0.5 \%$ hyperbaric bupivacaine, a local anaesthetic. ${ }^{2}$ The addition of intrathecal fentanyl (10-20 mg), an opioid, may reduce the dose of bupivacaine and thereby reducing the intraoperative complications. ${ }^{2}$ Slight Trendelenburg positioning facilitates achieving a T4 sensory level and may also helps to prevent severe hypotension. Though spinal anaesthesia is popular because of its simple technique, fast and highly effective anaesthesia avoiding general anaesthesia, but it is associated with some major or minor complications in the pregnant patient, the commonest being maternal hypotension. It is believed to occur in up to $95 \%$ of the patients and may lead to a reduction in utero-placental perfusion resulting in fetal acid-base abnormalities. $^{3}$

It has been well documented that combination of opioids and local anaesthetics administered intrathecally has a synergistic analgesic effect. ${ }^{4,5}$ Intrathecal fentanyl has faster onset of action, it improves quality of intraoperative analgesia and also helps to reduce intrathecal dose of local anaesthetic drugs. Intrathecal fentanyl is associated with less side effects and good postoperative analgesia and also have some favourable effects on haemodynamic stability. 6,7

The aim of this study was to compare and determine the efficacy of spinal anaesthesia with bupivacaine alone and low dose bupivacaine with adjuvant fentanyl.

\section{Materials and method}

This prospective study included 60 ASA (American Society of Anesthesiologist) physical status grade I \& II healthy pregnant mothers between 18 and 35 years of age scheduled for elective/emergency caesarean section. This randomized controlled clinical trial was carried out from January 2013 to December 2013 in two private hospitals of Mirpur, Dhaka, Bangladesh. Complicated pregnancies such as multiple pregnancy, severe anaemia, pregnancy induced hypertension, placenta praevia and patients with severe cardiac, renal disease, or taking anticoagulant were excluded from the study. At the operation theatre each patient received $10 \mathrm{mg}$ metoclopramide intravenously before spinal block and a rapid loading dose of intravenous infusion of $10 \mathrm{~mL} / \mathrm{kg}$ of Hartman solution via $18 \mathrm{G}$ intravenous cannula and the infusion was continued at a slower rate during the operation. Monitors like pulse oximeter, noninvasive blood pressure (NIBP) were used. Baseline pulse rate, blood pressure, respiratory rate, oxygen saturation values were recorded. The lumbar puncture was performed at the L2-L3 or L3-L4 interspace, with a $27 \mathrm{G}$ spinocain B. Braun ${ }^{\circledR}$ needle, with the patients in sitting position. After confirming the correct placement of the spinal needle by free flowing of the cerebrospinal fluid (CSF), the drug was injected intrathecally over 15-20 seconds, and the patients were immediately turned to supine position with slight Trendelenburg position, with 15 to 20 degrees of left uterine tilt and oxygen was given via face mask with a flow rate of $5 \mathrm{~L} / \mathrm{min}$.

The subjects were randomly divided into two groups with 30 subjects in each. Group-A received $12.5 \mathrm{mg}(2.5 \mathrm{ml})$ of $0.5 \%$ hyperbaric bupivacaine and group-B received $8 \mathrm{mg}(1.6 \mathrm{~mL})$ of $0.5 \%$ hyperbaric bupivacaine in combination with fentanyl $20 \mu \mathrm{gm} \quad(2.0 \mu \mathrm{mL})$. Intraoperative monitoring of pulse rate, respiratory rate, blood pressure, oxygen saturation were done at $1,3,5$, 15, 30, 60, and $90 \mathrm{~min}$. Blood pressure was measured via the NIBP monitor at $3 \mathrm{~min}$. Whenever systolic blood pressure was less than 90 $\mathrm{mm}$ of $\mathrm{Hg}$ or $25 \%$ below the baseline systolic blood pressure level (defined as hypotension), 5-10 $\mathrm{mg}$ of vasopressor (ephedrine) was administered intravenously. The number of hypotensive measurements and requirement of ephedrine for the patients were recorded. 
Sensory block assessment - sensory level was tested using hypodermic needle by pin prick method. Motor block assessment - the onset of motor block was defined as the time from the injection of drug in subarachnoid space till the patient was unable to raise the extended legs. The degree of motor block was assessed using Bromage Scale $(\mathrm{BS})^{8}$ [BS Grade 0: no motor block, Grade 1: inability to raise the extended legs, Grade 2: inability to flex the knee, able to flex the ankle, Grade 3: inability to flex the ankle i.e. complete motor block]. Recovery from motor block was recorded every 15 min Duration of motor block was calculated from starting to the recovery of motor block.

Assessment of analgesia - during postoperative period the patients were evaluated for pain with visual analogue scale (VAS) ${ }^{9}[0$ to $10 ; 0=$ no pain, $10=$ worst pain]. Duration of analgesia was considered as the time taken from the performance of subarachnoid block to the time of patient's first on demand analgesic drug for pain. Intraoperative patient's comfort was assessed in the postoperative room 30 minute after surgery with visual analogue scale $[0=$ total uncomfortable, $10=$ total comfortable].

Inj. Piton $\mathrm{DS}^{\circledR}$ (oxytocin) 10 units was given to all patients after delivery of the baby.

Emetic effects - nausea or vomiting and other side effects if any were recorded.

For assessment of fetal outcome 'APGAR' score system - described by Dr. Virginia Apgar, an anaesthesiologist - was adopted in this study. ${ }^{10,11}$ The 'APGAR' score were assessed at $1 \mathrm{~min}$ and 5 min after birth of the newborn and resuscitation measures were taken where necessary.

Unpaired t-test was done to assess quantitative factors while chi-square test was done to assess qualitative factors. $p$ value $<0.05$ was set to be as level of significance.

\section{Results}

There were 30 patients in each group of total 60 patients, and there were no significant differences between two groups with respect to age, weight, height and time required for operation (Table I).

Table I: Demographic characteristics $(N=60)$

\begin{tabular}{lccc}
\hline Variables & \multicolumn{2}{c}{ Mean \pm SD } & p value \\
& $\begin{array}{c}\text { Group-A } \\
(\mathbf{n}=\mathbf{3 0})\end{array}$ & $\begin{array}{c}\text { Group-B } \\
(\mathbf{n}=\mathbf{3 0})\end{array}$ & \\
\hline Age (years) & $24.70 \pm 4.95$ & $24.43 \pm 5.68$ & 0.837 \\
Weight $(\mathrm{kg})$ & $62.96 \pm 6.08$ & $63.89 \pm 9.47$ & 0.654 \\
Height $(\mathrm{cm})$ & $154.43 \pm 3.40$ & $155.20 \pm 4.59$ & 0.468 \\
Duration of operation (min) & $62.5 \pm 9.5$ & $60.0 \pm 15.0$ & 0.78 \\
\hline
\end{tabular}

Table II: Comparison of sensory and motor block characteristics

\begin{tabular}{lccc}
\hline Parameters & \multicolumn{2}{c}{ Mean \pm SD } & p value \\
& $\begin{array}{c}\text { Group-A } \\
(\mathbf{n}=\mathbf{3 0})\end{array}$ & $\begin{array}{c}\text { Group-B } \\
(\mathbf{n}=\mathbf{3 0})\end{array}$ & \\
\hline Onset of sensory block (sec) & $78 \pm 8.21$ & $75 \pm 9.23$ & $>0.05$ \\
Peak level of sensory analgesia (T) & $6.23 \pm 0.65$ & $6.21 \pm 0.75$ & $>0.05$ \\
Time for peak sensory level (min) & $6.30 \pm 1.30$ & $5.02 \pm 0.81$ & $<0.05$ \\
Degree of analgesia (grade) & $3.85 \pm 0.35$ & $3.95 \pm 0.17$ & $>0.05$ \\
Onset time for motor block (sec) & $82.60 \pm 12.7$ & $84.30 \pm 11.9$ & $>0.05$ \\
\hline
\end{tabular}

Time required for onset of sensory analgesia and peak level of sensory analgesia were comparable in both the groups $(p>0.05)$. The mean time required to reach peak sensory level was earlier in group-B than group-A and it was statistically significant $(p<0.05)$. The quality of analgesia was better in group-A compared to group-B but was not statistically significant. Complete motor block was achieved in all patients of both the groups.

Table III: Comparison of haemodynamic status

\begin{tabular}{lccc}
\hline Parameters & \multicolumn{2}{c}{ Mean \pm SD } & p value \\
& $\begin{array}{c}\text { Group-A } \\
(\mathbf{n}=\mathbf{3 0})\end{array}$ & $\begin{array}{c}\text { Group-B } \\
(\mathbf{n}=\mathbf{3 0})\end{array}$ & \\
\hline Basal pulse rate (min) & $90.66 \pm 7.81$ & $92.05 \pm 7.28$ & $>0.05$ \\
Minimum pulse rate (min) & $86.86 \pm 4.69$ & $84.26 \pm 2.88$ & $>0.05$ \\
Basal SBP (mm of Hg) & $118.80 \pm 13.41$ & $114.70 \pm 13.62$ & $>0.05$ \\
Minimum SBP (mm of Hg) & $92.83 \pm 9.69$ & $102.50 \pm 10.60$ & $<0.05$ \\
Basal DBP (mm of Hg) & $82.76 \pm 12.71$ & $80.83 \pm 5.33$ & $>0.05$ \\
Minimum DBP (mm of Hg) & $62.01 \pm 4.48$ & $62.80 \pm 3.11$ & $>0.05$ \\
Basal respiratory rate (breaths/min) & $20.48 \pm 1.28$ & $19.73 \pm 1.78$ & $>0.05$ \\
Minimum respiratory rate (breaths/min) & $18.28 \pm 2.46$ & $16.27 \pm 1.42$ & $>0.05$ \\
Basal oxygen saturation (\%) & $97.5 \pm 0.6$ & $97.1 \pm 1.2$ & $>0.05$ \\
Minimal oxygen saturation (\%) & $96.6 \pm 0.9$ & $96.5 \pm 1.1$ & $>0.05$
\end{tabular}

$\mathrm{SBP}=$ Systolic blood pressure

$\mathrm{DBP}=$ Diastolic blood pressure 
The decrease in systolic blood pressure in group-A was significantly more than in group- $\mathrm{B}(\mathrm{p}<0.05)$. The above table values demonstrated that there were no significant differences in diastolic blood pressure, respiratory rate, and oxygen saturation in both the groups.

Table IV: Comparison of treatment of hypotension between two groups

\begin{tabular}{|c|c|c|c|}
\hline \multirow[t]{2}{*}{ Age group } & \multicolumn{2}{|c|}{ Requirement of vasopressor } & \multirow[t]{2}{*}{$p$ value } \\
\hline & Yes & No & \\
\hline$A(n=30)$ & 8 & 22 & \multirow{2}{*}{$<0.05$} \\
\hline$B(n=30)$ & 2 & 28 & \\
\hline
\end{tabular}

Significantly more patients required vasopressor in group-A than group-B $(\mathrm{p}<0.05)$.

Table V: Comparison of sensory and motor recovery between two groups

\begin{tabular}{lccc}
\hline Variables & \multicolumn{2}{c}{ Mean \pm SD } & p value \\
& $\begin{array}{c}\text { Group-A } \\
(\mathbf{n}=\mathbf{3 0})\end{array}$ & $\begin{array}{c}\text { Group-B } \\
(\mathbf{n}=\mathbf{3 0})\end{array}$ & \\
\hline $\begin{array}{l}\text { Time for two segment } \\
\text { regression (min) }\end{array}$ & $66.0 \pm 11.04$ & $82.66 \pm 12.02$ & $<0.05$ \\
$\begin{array}{l}\text { Time for sensory } \\
\text { recovery (min) }\end{array}$ & $104.42 \pm 6.08$ & $119.3 \pm 12.2$ & $<0.05$ \\
$\begin{array}{l}\text { Time for motor } \\
\text { recovery (min) }\end{array}$ & $88.72 \pm 7.61$ & $75.8 \pm 13.9$ & $<0.05$ \\
\hline
\end{tabular}

Mean time of two segment regression of sensory analgesia and complete sensory recovery and the mean duration of motor recovery in group-B were significantly earlier $(\mathrm{p}<0.05)$.

Table VI: Comparison of duration of analgesia, comfort score between the groups

\begin{tabular}{lccc}
\hline Variables & \multicolumn{2}{c}{ Mean \pm SD } & p value \\
& $\begin{array}{c}\text { Group-A } \\
(\mathbf{n = 3 0})\end{array}$ & $\begin{array}{c}\text { Group-B } \\
(\mathbf{n}=\mathbf{3 0})\end{array}$ & \\
\hline Duration of analgesia $(\mathrm{min})$ & $120.23 \pm 4.48$ & $240.28 \pm 39.46$ & $<0.05$ \\
Comfort score & $8.86 \pm 0.44$ & $8.96 \pm 0.12$ & $>0.05$ \\
\hline
\end{tabular}

Duration of effective analgesia was significantly more in group-B $(\mathrm{p}<0.05)$. Patient's comfort score in group-B was better though not significant $(\mathrm{p}>0.05)$.

Table VII: Neonatal outcome after caesarean delivery

\begin{tabular}{lccc}
\hline Variables & \multicolumn{2}{c}{ Mean \pm SD } & p value \\
& $(\mathbf{n = 3 0 )}$ & $\begin{array}{c}\text { Group-B } \\
(\mathbf{n}=\mathbf{3 0})\end{array}$ & \\
\hline At 1 min & $9.46 \pm 0.81$ & $9.53 \pm 0.73$ & $>0.05$ \\
At 5 min & $9.80 \pm 0.54$ & $9.90 \pm 0.30$ & $>0.05$ \\
\hline
\end{tabular}

APGAR scores at 1 min and 5 min were similarly excellent in both the groups and were statistically not significant.

Table VII: Side effect observed between two groups

\begin{tabular}{lcc}
\hline Events & Group-A & Group-B \\
\hline Nausea & $4(13.33 \%)$ & 00 \\
Vomiting & $2(6.7 \%)$ & 00 \\
Hypotension & $8(26.6 \%)$ & $2(6.7 \%)$ \\
Shivering & $4(13.3 \%)$ & 00 \\
Purities & 00 & $4(13.33 \%)$ \\
\hline
\end{tabular}

Data were presented as frequencies. Incidence of nausea and vomiting was low in group-B due to better haemodynamic stability than group-A. In respect to hypotension $6.7 \%$ patients in group-B required ephedrine to counter the hypotension compared to $26.67 \%$ in group-A. Pruritus was observed only in group-B (13.33\%). Incidence of shivering occurred in $4(13.3 \%)$ patients in groupA as compared to none in group- B.

\section{Discussion}

A wide variety of adjuvant agents are used along with local anaesthetic mixtures to enhance and prolong their action, to reduce unwanted motor weakness and autonomic dysfunction and to reduce central nervous system and cardiovascular toxicity. The most widely used adjuvants are opioids agonist like morphine, fentanyl, $\alpha 2$ adrenergic agonist like clonidine, epinephrine, anti-cholinergic agent like neostigmine, NMDA receptor antagonist like ketamine and $\mathrm{MgSO}_{4}$. Whatever any adjuvant is used, it should be preservative free, nontoxic to neuron and should not contain any inhibitory neurotransmitters. ${ }^{12}$

In this study, mean time of onset of sensory blockade and peak level of analgesia were similar in both the groups. Peak level of analgesia varied between T6-T10. Addition of fentanyl with bupivacaine did not alter onset as well as height of block. Bogra et al. ${ }^{13}$ and Agarwal et al. ${ }^{14}$ also got similar results. In our study the time to reach peak sensory level was earlier in group-B than in group-A. This is because opioids have synergistic effect with local anaesthetics. ${ }^{15}$ Local 
anaesthetics block $\mathrm{Na}^{+}$channels and opioids block the voltage gated $\mathrm{Ca}^{++}$channels. Shende et al. ${ }^{15}$ found in their study that sensory block to T4 was achieved after $6.5 \mathrm{~min}$ in those who received fentanyl compared to $8 \mathrm{~min}$ in the group who did not. This trend was consistent with the present study. Similar results were found by Dahlgren et al. ${ }^{7}$ and Agarwal et al. ${ }^{14}$ Better degree of analgesia in group-B was seen in our study because of synergism of fentanyl with bupivacaine and fentanyl also enhances abolishing visceral pain. Bogra et al. ${ }^{13}$ found in their study that bupivacaine alone could not completely abolish visceral pain, whereas bupivacaine and fentanyl combination was effective. All the patients had grade III motor blockade. Fentanyl added to bupivacaine had no effect to enhance either onset or degree of motor blockade. Bogra et al. ${ }^{13}$ and Dahlgren et al. ${ }^{7}$ also found that onset and degree of motor block was comparable in their study groups.

Haemodynamic variables (heart rate, blood pressure, $\mathrm{SPO}_{2}$ ) remain unchanged after large anaesthetic dose of fentanyl. Fentanyl induced bradycardia is due to stimulation of central vagal nucleus. None of the patients had bradycardia in both the groups. This may be due to the use of low dose fentanyl. There was no incidence of significant bradycardia in studies conducted by Dahlgren et al. ${ }^{7}$, Bogra et al. ${ }^{13}$ and Agarwal et al. ${ }^{14}$ Bogra et al. ${ }^{13}$ found that blood pressure declined with increasing concentration of bupivacaine and fentanyl. David et al. ${ }^{16}$ found that patients with plain bupivacaine were more likely to require treatment of hypotension (94\% vs. $31 \%$ ) and had more persistent hypotension (4.8 Vs 0.6 hypotension number/per patient) than patients with low dose bupivacaine-fentanyl group. In our study similar result was found. Incidence of hypotension was more in group-A as compared to group-B. All the patients received $\mathrm{O}_{2} 5 \mathrm{~L} / \mathrm{min}$ intraoperatively for $24 \mathrm{hrs}$ and postoperatively no respiratory depression was observed. Belzarena ${ }^{5}$ found that although no patient develops respiratory depression, respiratory rate changes increased with the dose of fentanyl and they suggested that large doses might be associated with respiratory depression.
Mean time of two segment regression and complete sensory recovery was significantly prolonged in group-B as opioids have synergistic effect with local anaesthetics. Belzarena ${ }^{5}$ concluded that time to regression below T12 dermatome was longer in treated group and increased with increasing dose of fentanyl. The prolonged sensory block suggests synergism between fentanyl and bupivacaine as seen with other opioids and local anaesthetics. ${ }^{14}$ Motor recovery was earlier in group-B. Dahlgren et al. ${ }^{7}$ also found slightly earlier motor recovery in fentanyl group compared to placebo group. Motor recovery was earlier in group-B because of low dose bupivacaine. Early motor recovery and mobilization also increases patient's comfort as well as emotional and psychological disturbances.

In this study we found significantly prolonged duration of effective analgesia in group- $\mathrm{B}$ as compared to group-A. Belzarena ${ }^{5}$, Bogra et al. ${ }^{13}$, Shende et al. ${ }^{15}$, and Hunt et al. ${ }^{17}$ found prolonged duration of effective analgesia and less analgesic requirement in postoperative period in bupivacaine fentanyl combination group. Prolonged effective analgesia suggests synergism between fentanyl and bupivacaine. ${ }^{14}$

Intraoperative comfort score was assessed using VAS which was slightly better in group-B. Shende et al. ${ }^{15}$ also observed that quality of intraoperative surgical anaesthesia improved significantly in fentanyl group compared to control group. This is due to the effect of fentanyl in abolishing pain, and providing better quality of surgical anaesthesia and haemodynamic stability.

Considering addition of lipid soluble narcotics with local anaesthetics like fentanyl in higher doses $(>100 \mu \mathrm{gm})$ may lead to changes in fetal heart rate. Whereas low dose, single injection narcotics appears to be safe. ${ }^{10}$ No neonatal depression was seen in our study. The APGAR score at $1 \mathrm{~min}$ and $5 \mathrm{~min}$ were excellent in both the groups. Bogra et al. ${ }^{13}$, Shende et al. ${ }^{15}$, and Dahlgren et al. ${ }^{7}$ reported similar observation.

In our study the incidence of nausea and vomiting was low in group-B due to better haemodynamic 
stability than group-A. Two $(6.7 \%)$ patients in group-B required ephedrine to counter the hypotension compared to $8(26.67 \%)$ in group-A. Comparison of hypotension between groups were statistically significant $(\mathrm{p}<0.05)$. Incidence of hypotension was less in group-B, this is due to use of low dose bupivacaine and fentanyl also has no effect on sympathetic block. ${ }^{4}$ Pruritus was seen only in group-B (13.33\%). The same result was observed in a study conducted by Hunt et al. ${ }^{17}$ In other studies Dahlgren et al. ${ }^{7}$ and Agarwal et al. ${ }^{14}$ also noted pruritus as a side effect of intrathecal opioids and was more associated with sufentanyl than fentanyl. No patients in group-B had shivering compared to $4(13.33 \%)$ patients in group-A. Techanivate et al. ${ }^{18}$ conducted study on intrathecal fentanyl for prevention of shivering in caesarean section. They used $20 \mu \mathrm{gm}$ fentanyl intrathecally in spinal anaesthesia for caesarean section. They demonstrated that reduction in shivering was due to effect of fentanyl that was added into the subarachnoid space which could affect afferent thermal inputs at the spinal cord. Opioids also stimulate cAMP formation which increases the thermal sensitivity to warm sensation and modulate slope temperature insensitive neuron. ${ }^{19}$

In conclusion, the findings of this study suggest that spinal anaesthesia for caesarean delivery using low dose hyperbaric bupivacaine in combination with fentanyl is associated with significantly less hypotension, vasopressor requirements and nausea than spinal anaesthesia with conventional dose of hyperbaric bupivacaine and without any untoward effects. This combination has been shown to improve the quality of spinal anaesthesia for caesarean delivery. Even then large multicenter study is encouraged to verify a reliable minimum dose of bupivacaine with fentanyl for spinal anaesthesia in caesarean delivery.

\section{References}

1. Morgan Jr. GE, Mikhail MS, Murray MJ. Obstetric Anesthesia. In: Clinical Anesthesiology. $4^{\text {th }}$ ed. New York: McGraw-Hill; 2005.p.902.
2. Rachel AF, Shankar KB. Anesthesia. In: Healy TEJ, Knight PR, editors. Wylie Churchill-Davidson's A practice of Anesthesia. $7^{\text {th }}$ ed. London: Arnold; 2003.p.930.

3. Ben-David B, Solomon E, Levin H, Admoni H, Goldik Z. Intrathecal Fentanyl with Small-Dose Dilute Bupivacaine: Better Anesthesia without Prolonging Recovery. Anesth Analg. 1997;85:560-65.

4. Wang C, Chakrabarti MK, Whitwam JG. Specific Enhancement by Fentanyl of the Effects of Intrathecal Bupivacaine on Nociceptive Afferent but Not on Sympathetic Efferent Pathways in Dogs. Anesthesiology. 1993;79(4):766-73.

5. Belzarena SD. Clinical Effects of Intrathecally Administered Fentanyl in Patients Undergoing Caesarean Section. Anesth Analg. 1992;74(5):653-57.

6. Courtney MA, Bader AM, Hartwell B, Hauck M, Grennan MJ, Datta S. Perioperative Analgesia with Subarachnoid Sufentanyl Administration. Reg Anesth. 1992;17:274-78.

7. Dahlgren G, Hultstrand C, Jacobson J, Norman M, Eriksson EW, Martin H. Intrathecal Sufentanil, Fentanyl or Placebo Added to Bupivacaine for Caesarean Section. Anesth Analg. 1997;85(6): 1288-93.

8. Brown DL. Regional Anaesthesia and Analgesia in Practice. In: Regional Anaesthesia and Analgesia. $1^{\text {st }}$ ed. Philadelphia PA: WB Saunders Company; 1996.p.582.

9. Rosenberg AD, Grande CM, Bernstein RL, editors. Text Book of Pain Management and Regional Anesthesia in Trauma. Philadelphia PA: WB Saunders Company; 1999.p.111-21.

10. Churchill-Davidson HC, Wiley WD. A Practice of Anaesthesia. $5^{\text {th }}$ ed. Churchill-Davidson HC, editor. London: Lloyd-Luke (Medical Books) Ltd; 1984.p.1094-96.

11. Behrman RE, Klingman RM, Nelson WE, Vaughan VC, editors. Nelson Textbook of Pediatrics. 14th ed. Philadelphia PA: WB Saunders; 1992.p.432-60.

12. Shudhakar RM, Mathew RC. Adjuvant Agents in Regional Anesthesia. Anaesthesia and Intensive Care Medicine. 2009;10:538-40. 
13. Bogra J, Arora N, Srivastava P. Synergistic Effect of Intrathecal Fentanyl and Bupivacaine in Spinal Anesthesia for Cesarean Section. BMC Anesthesiol. 2005;5(1):5.

14. Agrawal A, Agrawal S, Asthana V, Payal YS, Jagdish S, Gupta V. Comparison of Intrathecal Fentanyl and Sufentanil in Addition to Bupivacaine for Caesarean Section Under Spinal Anaesthesia. J Anaesth Clin Pharmacol. 2009;25(2):154-56.

15. Shende D, Copper GM, Bowden MI. The Influence of Intrathecal Fentanyl on the Characteristics of Subarachnoid Block for Caesarean Section. Anesthesia. 1988;53(7):706-10.

16. Ben-David B, Miller G, Gavriel R, Gurevitch A.
Low-Dose Bupivacaine-Fentanyl Spinal Anesthesia for Cesarean Delivery. Reg Anesth Pain Med. 2000;25(3):235-39.

17. Hunt CO, Naulty S, Bader AM, Hauch M, Verticar JV, Datta S, et al. Perioperative Analgesia with Subarachnoid Fentanyl-Bupivacaine for Caesarean Delivery. Anesthesiology. 1989;71:535-40.

18. Techanivate A, Rodanant O, Tachawattanawisal W, Somsiri T. Intrathecal Fentanyl for Prevention of Shivering in Cesarean Section. J Med Assoc Thai. 2005;88(9):1214-21.

19. De Witte J, Sessler DI. Perioperative Shivering: Physiology and Pharmacology. Anaesthesiology. 2002;96(2):467-84. 